Research

Open Access

\title{
Procalcitonin kinetics within the first days of sepsis: relationship with the appropriateness of antibiotic therapy and the outcome
}

\author{
Pierre Emmanuel Charles ${ }^{1}$, Claire Tinel ${ }^{1}$, Saber Barbar ${ }^{1}$, Serge Aho², Sébastien Prin ${ }^{1}$, \\ Jean Marc Doise ${ }^{1}$, Nils Olivier Olsson ${ }^{3}$, Bernard Blettery ${ }^{1}$ and Jean Pierre Quenot ${ }^{1}$
}

\author{
1Service de Réanimation Médicale, Hôpital Le Bocage, C.H.U. de Dijon, 21000 Dijon, France \\ 2Service d'Epidémiologie et d'Hygiène Hospitalière, Hôpital Le Bocage, C.H.U. de Dijon, 21000 Dijon, France \\ ${ }^{3}$ Laboratoire d'Immunologie, Hôpital Le Bocage, C.H.U. de Dijon, 21000 Dijon, France \\ Corresponding author: Pierre Emmanuel Charles, pierre-emmanuel.charles@chu-dijon.fr
}

Received: 2 Jan 2009 Revisions requested: 3 Feb 2009 Revisions received: 19 Feb 2009 Accepted: 16 Mar 2009 Published: 16 Mar 2009

Critical Care 2009, 13:R38 (doi:10.1186/cc7751)

This article is online at: http://ccforum.com/content/13/2/R38

(C) 2009 Charles et al.; licensee BioMed Central Ltd.

This is an open access article distributed under the terms of the Creative Commons Attribution License (http://creativecommons.org/licenses/by/2.0), which permits unrestricted use, distribution, and reproduction in any medium, provided the original work is properly cited.

\begin{abstract}
Introduction Management of the early stage of sepsis is a critical issue. As part of it, infection control including appropriate antibiotic therapy administration should be prompt. However, microbiological findings, if any, are generally obtained late during the course of the disease. The potential interest of procalcitonin (PCT) as a way to assess the clinical efficacy of the empirical antibiotic therapy was addressed in the present study.

Methods An observational cohort study including 180 patients with documented sepsis was conducted in our 15-bed medical intensive care unit (ICU). Procalcitonin measurement was obtained daily over a 4-day period following the onset of sepsis (day 1 (D1) to D4). The PCT time course was analyzed according to the appropriateness of the first-line empirical antibiotic therapy as well as according to the patient outcome.

Results Appropriate first-line empirical antibiotic therapy ( $\mathrm{n}=$ 135) was associated with a significantly greater decrease in PCT between D2 and D3 ( $\triangle$ PCT D2-D3) (-3.9 (35.9) vs. +5.0 (29.7), respectively; $P<0.01)$. In addition, $\triangle$ PCT D2-D3 was found to be an independent predictor of first-line empirical antibiotic therapy appropriateness. In addition, a trend toward a
\end{abstract}

greater rise in PCT between D1 and D2 was observed in patients with inappropriate antibiotics as compared with those with appropriate therapy $(+5.2 \quad(47.4)$ and +1.7 (35.0), respectively; $P=0.20)$. The D1 PCT level failed to predict outcome, but higher levels were measured in the nonsurvivors ( $\mathrm{n}$ $=51)$ when compared with the survivors $(n=121)$ as early as D3 (40.8 (85.7) and 21.3 (41.0), respectively; $P=0.04$ ). Moreover, PCT kinetics between D2 and D3 were also found to be significantly different, since a decrease $\geq 30 \%$ was expected in the survivors (log-rank test, $P=0.04$ ), and was found to be an independent predictor of survival (odds ratio $=2.94 ; 95 \%$ confidence interval 1.22 to $7.09 ; P=0.02$ ).

Conclusions In our study in an ICU, appropriateness of the empirical antibiotic therapy and the overall survival were associated with a greater decline in PCT between D2 and D3. Further studies are needed to assess the utility of the daily monitoring of PCT in addition to clinical evaluation during the early management of sepsis.

\section{Introduction}

Bacterial sepsis is a leading cause of morbidity and death among critically ill patients [1-3]. Since the first days of the management of such patients are thought to be critical, both clinical and biological objectives are required to optimize therapies [4-6]. Cumulative evidence supports the fact that severe sepsis arises from the inability of the host to control bacterial growth as well as from an overwhelming inflammatory response that could itself subsequently cause remote organ dysfunction [7]. Eradicating the bacterial invader as well as keeping in check the host's immune response over these socalled golden hours of sepsis are therefore believed to be critical issues. Accordingly, the early administration of appropriate antibiotics leads to a significant improvement in the outcome 
of the patients with sepsis [8,9]. At least 48 hours, however, are generally required to accurately identify the bacteria, if any, as well as the susceptibility to antimicrobial agents. In addition, the appropriateness of the host response is far more difficult to appreciate routinely.

Elevated levels of serum procalcitonin (PCT), a 116-aminoacid peptide, are strongly associated with systemic bacterial infections [10]. In addition, PCT elevation is thought to be closely dependent on the host cytokine response to microbial challenge, which could be mitigated by the antibacterial effect of antibiotics. Furthermore, the magnitude and time course of this response could be closely related to patient outcome $[11,12]$. Two studies have emphasized that the relationship between the daily variations of PCT could affect sepsis management regarding the length of antibiotic therapy [13,14]. Little is known, however, about PCT behavior in septic patients according to the appropriateness of the first-line antibiotic therapy. In addition, previously published studies are sparse and provide conflicting results regarding the prognosis value of PCT [15-21].

We therefore conducted an observational study in our 15-bed medical intensive care unit (ICU) to assess to which extent an appropriate empirical antimicrobial therapy could hasten the PCT decrease within the first days of sepsis management.

\section{Materials and methods Study population}

Every episode of bacteremia, community-acquired pneumonia and ventilator-associated pneumonia (VAP), as defined below, was prospectively recorded by one of the investigators (PEC) in our ICU throughout the study period, for an epidemiological survey. In addition, PCT dosage was usually performed daily in every patient with suspected sepsis as a reliable tool to improve diagnosis and antimicrobial management [13]. In accordance with French law, no informed consent was required since all measurements were part of routine management. Accordingly, our local Ethics Committee approved the study.

Every patient with either bacteremia, community-acquired pneumonia or VAP, as defined below, on admission to or during the stay in the ICU was therefore eligible for the study if the PCT dosage had been obtained at the onset of clinical sepsis according to the American College of Chest Physicians/Society of Critical Care Medicine Consensus Conference (that is, day 1 (D1)) and at least twice more within next 3 days. No rule was applied regarding the availability of C-reactive protein dosages since our study focused on PCT. Only patients with proven bacterial infection as described below were kept for further analysis, provided they had not received any appropriate antibiotics during the 48 hours prior to the diagnosis of sepsis.
The following information was prospectively collected: the main clinical and epidemiological data at ICU admission, such as age, gender, type of admission (admission was considered surgical in patients who had undergone surgery within the 30 days preceding the onset of bloodstream infection, and medical otherwise), and severity of illness on admission expressed by the Simplified Acute Physiology Score (SAPS) II; patient characteristics at the onset of sepsis and then daily until D4, including main biological results, the septic condition (that is, sepsis, severe sepsis or septic shock), and organ dysfunction expressed by the Sepsis-related Organ Failure Assessment (SOFA) score; the infection source, if known; microbiological findings; and outcome in the ICU (that is, death or discharge).

Other data were collected retrospectively. Each medical chart was therefore reviewed by an external observer (CT), unaware of the purpose of the study, following a standard record sheet. The available PCT measurements were then recorded. Antimicrobial susceptibility testing reports were reviewed by an expert in infectious disease (PEC) unaware of the PCT values as well as of the outcome, in order to determine the appropriateness of the antibiotics administered to the patient as defined below.

\section{Definitions}

One episode of bacteremia was defined as the recovery of any bacterial species, in one or more blood cultures. Patients in whom Staphylococcus non-aureus were isolated in blood cultures were not eligible, except if at least two consecutive samples grew for the same species harboring the same antibiotic resistance pattern. Blood samples were obtained by blood punctures before being processed using the BACTEC system based both on standard aerobic and anaerobic media coupled with the 9240 automate (Beckton Dickinson Diagnostic Instrument System, Paramus, NJ, USA). Bacteria identification was based on standard methods. The onset of bacteremia was defined as the day when the first positive blood culture was obtained. Two distinct episodes of bloodstream infection were considered in one patient if at least 6 days had elapsed between the two sets of positive blood cultures, provided appropriate therapy was implemented and significant clinical improvement was obtained between the two episodes. This time interval was chosen since previously published data indicate that blood culture negativation is obtained in a median time of around 2 days in patients with bacteremia receiving appropriate antimicrobial treatment.

VAP was considered in every patient submitted to mechanical ventilation for more than 2 days if the following conditions were present: new lung infiltrate on the chest $X$-ray scan; positive tracheal aspirate cultures $\left(>10^{6}\right.$ colony forming units $\left./ \mathrm{ml}\right)$; and Clinical Pulmonary Infection Score $>6$ points.

Community-acquired pneumonia was considered in every patient presenting on admission with lung infiltrate on the 
chest $\mathrm{X}$-ray scan, a history of respiratory symptoms and the presence of a putative lung pathogen within the respiratory secretions and/or a positive urinary antigene for Streptococcus pneumoniae or Legionella pneumophila serotype 1 using the corresponding Binax assay.

In patients with bacteremia, other septic states were considered according to standard definitions if considered as the infection source (for example, catheter related-bacteremia, urinary tract infection, and so forth).

Sepsis was considered nosocomial if it had appeared more than 2 days after hospital admission.

\section{Main endpoints}

The main clinical endpoint was the appropriateness of the antibiotic therapy given within the first 24 hours following the onset of sepsis (that is, first-line empirical antibiotic therapy). The empirical antibiotic therapy was considered appropriate if the isolated pathogen(s) was (were) susceptible to at least one drug administered at the onset of sepsis according to the corresponding susceptibility testing report. The crude ICU mortality was also considered.

\section{Measurement of the procalcitonin level}

The Kryptor ${ }^{\circledR}$ immunoassay was used according to the manufacturer's instructions (Brahms, Hennigsdorf, Germany). The functional sensitivity of the assay is $0.06 \mathrm{ng} / \mathrm{ml}$. Patients for whom the PCT measurement was either unavailable or were not performed within the 12 hours following the blood sample were excluded from further analysis because of the risk of false-negative results.

\section{Statistical analysis}

Values are expressed as the mean \pm standard deviation unless otherwise stated. PCT levels were log-transformed for all analyses. PCT kinetics are expressed as $\triangle \mathrm{PCT}$ values. $\triangle \mathrm{PCT}$ was defined as the difference between two subsequent values. For example, $\triangle P C T$ D2-D3 was the difference in PCT between the second and third days ( $\triangle$ PCT D2-D3 = PCT-D3 - PCTD2) following the onset of sepsis (that is, D1). As a result, $\triangle$ PCT D2-D3 $>0$ if PCT had increased from D2 to D3. $\triangle P C T$ was also expressed as proportions. For example, $\triangle \mathrm{PCT}$ D2-D3 > 50\% meant that PCT has increased by more than $50 \%$ between D2 and D3.

Continuous variables were compared with the Mann-Whitney $U$ test. Categorical variables were compared using the chisquare test. We then examined the independent contribution of factors that had been predictive of death in the ICU by univariate analysis. Prior to logistical regression, conformity with the linear gradient of each continuous variable was checked. If the linear model was not appropriate to describe its variations, the variable was transformed according to the parcimonious rule. The candidate variables were then manually entered into a logistical regression model if the associated regression coefficient had $P<0.20$ by univariate analysis, and then removed if $P>0.05$ was obtained by multivariate analysis.

It is worth noting that the SAPS II was not entered into the model regardless of the value obtained by univariate analysis. Actually, it has been established that the SAPS II has been validated in a large cohort of patients with various conditions different from sepsis. As a result, although this score is thought to provide a reliable assessment of the mortality risk, it does not specifically measure the risk of death from infectious causes. In addition, since sepsis onset does not always occur on admission, the SAPS II value does not necessarily reflect a patient's condition at this time, especially in terms of organ dysfunction and failure. Actually, sepsis was an ICU-acquired condition in more than one-third of our patients (data not shown). Finally, the sequential measurement of the SAPS II has not yet been validated. The SOFA score was therefore calculated daily during the course of sepsis, and was preferred to the SAPS II as a predictive model of organ dysfunction and outcome. The survival of patients regarding the PCT decrease expressed as proportions were also analyzed through the construction of the corresponding Kaplan-Meier curves compared by the log-rank test.

The relationship between the PCT kinetics and the appropriateness of the first-line antibiotic therapy was investigated through the comparison of the $\triangle P C T$ values. A multivariate analysis was conducted following the same rules as described previously.

The diagnosis accuracy of $\triangle \mathrm{PCT}$ and SOFA for the distinction between survivors and nonsurvivors was then expressed as the area under the corresponding receiver operating characteristic curve.

$P<0.05$ was considered statistically significant for all analyses. STATA software was used for all analyses (College Station, TX, USA).

\section{Results Patients' characteristics}

Between 1 May 2005 and 31 June 2007, 319 patients presented with sepsis on admission to the ICU or during their stay in our ICU. Among these patients, 29 were excluded because the required PCT dosages were not available, 26 were excluded because fungi were isolated, 71 were excluded because bacterial cultures remained sterile and 13 were excluded because appropriate antibiotics had been given within the 48 hours preceding the onset of sepsis. The remaining 180 patients were considered eligible for further analysis.

The main baseline characteristics of the included patients are presented in Table 1. The main source of infection was found to be the lung (51.7\%). In more than one-half of the cases of 
Critical Care Vol 13 No 2 Charles et al.

Table 1

Baseline characteristics of patients with bacterial sepsis, appropriateness of first-line empirical antibiotic therapy, and outcome

\begin{tabular}{|c|c|c|c|c|c|}
\hline & \multirow{2}{*}{$\begin{array}{l}\text { Overall population ( } \mathrm{n} \\
=180 \text { ) }\end{array}$} & \multicolumn{2}{|c|}{ First-line empirical antibiotic therapy } & \multicolumn{2}{|l|}{ Outcome } \\
\hline & & Appropriate $(n=135)$ & Inappropriate $(n=45)$ & Survivors $(n=129)$ & Nonsurvivors $(n=51)$ \\
\hline Age (years) & $64.0(15.3)$ & $63.4(15.9)$ & $65.9(13.1)$ & $62.2(15.5)$ & $68.6(14.0)^{a}$ \\
\hline Sex (male/female) & $\begin{array}{l}122(67.8 \%) / 58 \\
(32.2 \%)\end{array}$ & $\begin{array}{l}87(64.4 \%) / 48 \\
(35.6 \%)\end{array}$ & $\begin{array}{l}35(77.8 \%) / 10 \\
(22.2 \%)^{\mathrm{b}}\end{array}$ & $\begin{array}{l}91(70.5 \%) / 38 \\
(29.5 \%)\end{array}$ & $\begin{array}{l}31(60.8 \%) / 20 \\
(39.2 \%)\end{array}$ \\
\hline $\begin{array}{l}\text { SAPS II on admission } \\
\text { (points) }\end{array}$ & $46.3(16.9)$ & $45.2(17.7)$ & $49.9(13.7)$ & $41.6(15.2)$ & $58.1(15.3)^{a}$ \\
\hline $\begin{array}{l}\text { Time between ICU } \\
\text { admission and sepsis } \\
\text { (days) }\end{array}$ & $4.7(8.9)$ & $4.9(9.7)$ & $4.1(5.8)$ & $3.8(8.1)$ & $7.1(10.3)^{a}$ \\
\hline \multicolumn{6}{|l|}{ Sepsis source } \\
\hline Pneumonia & $93(51.7 \%)$ & $68(54.4 \%)$ & $25(55.6 \%)$ & $59(45.7 \%)$ & $34(66.7 \%)^{a}$ \\
\hline Miscellaneous ${ }^{c}$ & $59(32.8 \%)$ & $43(31.8 \%)$ & $16(35.6 \%)$ & $47(36.4 \%)$ & $5(9.8 \%)$ \\
\hline Urinary tract & $28(15.5 \%)$ & $24(17.8 \%)$ & $4(8.8 \%)$ & $23(17.8 \%)$ & $12(23.5 \%)$ \\
\hline Bacteremia & $101(56.1 \%)$ & $72(53.3 \%)$ & $29(64.4 \%)$ & $73(56.6 \%)$ & $28(54.9 \%)$ \\
\hline \multicolumn{6}{|l|}{ Isolated pathogenes } \\
\hline Gram-negative & $87(48.3 \%)$ & $60(44.5 \%)$ & $29(60.0 \%)^{a}$ & $57(44.2 \%)$ & $30(58.8 \%)^{a}$ \\
\hline $\begin{array}{l}\text { Enterobacteriac } \\
\text { ae }\end{array}$ & $59(32.8 \%)$ & $39(28.9 \%)$ & $20(44.4 \%)$ & $43(33.3 \%)$ & $16(31.4 \%)$ \\
\hline $\begin{array}{l}\text { Pseudomonas } \\
\text { aeruginosa }\end{array}$ & $16(8.9 \%)$ & $12(8.9 \%)$ & $4(8.9 \%)$ & 7 (5.4\%) & $9(17.6 \%)$ \\
\hline Miscellaneous & $12(6.7 \%)$ & $9(6.7 \%)$ & $3(6.7 \%)$ & $7(5.4 \%)$ & $5(9.8 \%)$ \\
\hline Gram-positive & 79 (43.9\%) & $65(51.1 \%)$ & $14(31.1 \%)^{a}$ & $62(48.1 \%)$ & $17(33.3 \%)^{a}$ \\
\hline $\begin{array}{l}\text { Staphylococcus } \\
\text { aureus }\end{array}$ & $31(17.2 \%)$ & $28(20.7 \%)$ & $3(6.7 \%)$ & $23(17.8 \%)$ & $8(15.7 \%)$ \\
\hline $\begin{array}{l}\text { Streptococcus } \\
\text { spp. }\end{array}$ & $40(22.2 \%)$ & $33(24.4 \%)$ & 7 (15.5\%) & $32(24.8 \%)$ & $8(15.7 \%)$ \\
\hline Miscellaneous & $8(4.4 \%)$ & $4(3.0 \%)$ & $4(8.9 \%)$ & 7 (5.4\%) & $1(1.9 \%)$ \\
\hline Polymicrobial & $14(7.8 \%)$ & $10(7.4 \%)$ & $4(8.9 \%)$ & $10(7.7 \%)$ & $4(7.9 \%)$ \\
\hline \multicolumn{6}{|l|}{$\begin{array}{l}\text { Sepsis characteristics } \\
\text { by D1 }\end{array}$} \\
\hline Septic shock & $70(41.2 \%)$ & $57(42.2 \%)$ & $21(46.7 \%)$ & 39 (32.8\%) & $31(63.3 \%)^{a}$ \\
\hline $\begin{array}{l}\text { SOFA score } \\
\text { (points) }\end{array}$ & $6.2(3.6)$ & $6.2(3.5)$ & $6.2(3.9)$ & $5.4(3.2)$ & $8.2(3.5)^{a}$ \\
\hline $\begin{array}{l}\text { Platelet count } \\
\text { (giga/l) }\end{array}$ & $208.6(137.5)$ & $201.4(123.1)$ & $231.3(175.2)$ & $229.8(135.9)$ & $159.2(129.4)^{a}$ \\
\hline $\begin{array}{l}\mathrm{PaO}_{2} / \mathrm{FiO}_{2} \\
(\mathrm{mmHg})\end{array}$ & $244(140)$ & $229.2(129.7)$ & $285.3(161.0)^{a}$ & $256.3(140.1)$ & $217.9(139.2)^{b}$ \\
\hline $\begin{array}{l}\text { Mean arterial } \\
\text { pressure }(\mathrm{mmHg})\end{array}$ & $73.5(19.4)$ & $74.2(18.7)$ & $71.3(21.3)$ & $74.4(18.8)$ & $71.2(20.7)$ \\
\hline Lactate $(\mathrm{mmol} / \mathrm{l})$ & $3.2(2.9)$ & $3.4(3.2)$ & $2.7(1.8)$ & $2.8(2.6)$ & $4.1(3.4)^{a}$ \\
\hline $\begin{array}{l}\text { Bilirubinemia } \\
(\mu \mathrm{mol} / \mathrm{l})\end{array}$ & $28.3(43.8)$ & $30.8(47.9)$ & $20.5(26.1)$ & $28.6(48.8)$ & $27.7(28.5)$ \\
\hline $\begin{array}{l}\text { Creatininemia } \\
(\mu \mathrm{mol} / \mathrm{l})\end{array}$ & $199.1(181.2)$ & $197.6(184.2)$ & $203.6(173.5)$ & $204.7(196.4)$ & $184.9(135.9)$ \\
\hline
\end{tabular}


Table 1 (Continued)

\begin{tabular}{|c|c|c|c|c|c|}
\hline $\begin{array}{l}\text { C-reactive protein } \\
(\mathrm{mg} / \mathrm{l})\end{array}$ & $151.1(111.9)$ & $159.9(112.9)$ & $121.1(105.0)^{b}$ & $152.1(114.2)$ & $148.6(107.7)$ \\
\hline Nosocomial sepsis & $98(54.4 \%)$ & $70(51.8 \%)$ & $28(62.2 \%)$ & $64(49.6 \%)$ & $34(66.7 \%)^{b}$ \\
\hline ICU length of stay & $18.8(19.9)$ & $19.3(22.2)$ & $17.5(13.9)$ & $16.2(18.2)$ & $25.6(22.5)^{\mathrm{a}}$ \\
\hline
\end{tabular}

Baseline characteristics for 180 patients with bacterial sepsis, and description of the episodes according to the appropriateness of the first-line empirical antibiotic therapy and the outcome. D1, day sepsis is diagnosed; SAPS II, Simplified Acute Physiology Score II; SOFA, Sepsis-related Organ Failure Assessment; ICU, Intensive Care Unit. a $P<0.05$. ${ }^{b} P<0.20$. Includes soft tissue, central nervous system and catheter-related infections.

sepsis included, the diagnosis was bacteremia (56.1\%). Gram-negative bacteria and Gram-positive bacteria were isolated in the same proportions $(48.3 \%$ and $43.9 \%$ of all isolates, respectively). Gram-negative bacteria of the enterobacteriacae family were the most frequently isolated (32.8\% of all isolates). Gram-positive sepsis was mainly caused by Staphylococcus aureus and Streptococcus spp. (17.2\% and $22.2 \%$, respectively). The sepsis was polymicrobial in $7.8 \%$ of cases. Septic shock was present in $41.2 \%$ of the episodes.

Appropriateness of empirical first-line antibiotic therapy One-quarter of the patients were given inappropriate antibiotics within the first 24 hours of sepsis management (Table 1). The proportion of Gram-negative bacteria isolated was significantly higher in patients who did not receive appropriate antibiotics than in those who did $(60.0 \%$ vs. $44.5 \%$, respectively; $P=0.04$ ), whereas no difference existed in terms of severity of the disease as assessed by the SAPS II on admission as well as the D1 SOFA score.
Even though the magnitude of the PCT elevation between D1 and D2 seemed larger in patients who were given inappropriate empirical antibiotic therapy than in those who received active molecules, we failed to demonstrate any statistically significant difference (Table 2). In contrast, the PCT variation was significantly different between D2 and D3 (that is, $\triangle P C T$ D2-D3) $(P<0.01)$. In addition, the $\triangle$ PCT D2-D3 was found to be independently associated with antibiotic appropriateness by logistic regression (Table 3). Finally, PCT elevation by D4 was significantly lower in patients who had received appropriate antibiotics than in those who had not $(P=0.03)$.

In contrast, no difference was found from D1 to D4 if other potential relevant clinical or biological endpoints were considered (that is, SOFA score, platelet count, blood lactate concentration, mean arterial pressure, $\mathrm{PaO}_{2} / \mathrm{FiO}_{2}$, creatininemia, $\mathrm{C}$-reactive protein), as detailed in Table 4.

Table 2

Procalcitonin changes at various time points in patients with bacterial sepsis according to antibiotic therapy

\begin{tabular}{|c|c|c|c|}
\hline & \multicolumn{2}{|c|}{ First-line empirical antibiotic therapy } & \multirow[t]{2}{*}{$P$ value } \\
\hline & Appropriate & Inappropriate & \\
\hline PCT at D1 $(n=180 ; 129 \mathrm{~S}, 51 \mathrm{NS})^{a}$ & $27.2(62.7)$ & $29.6(96.7)$ & 0.92 \\
\hline PCT at $D 2(n=163 ; 117 \mathrm{~S}, 46 \mathrm{NS})^{a}$ & $27.4(45.1)$ & $40.9(74.3)$ & 0.09 \\
\hline$\triangle \mathrm{PCT}$ D1-D2 & $+1.7(35.0)$ & $+5.2(47.4)$ & 0.20 \\
\hline PCT at D3 $(n=164 ; 117 \mathrm{~S}, 47 \mathrm{NS})^{a}$ & $24.4(58.4)$ & $34.4(55.7)$ & 0.12 \\
\hline$\triangle \mathrm{PCT}$ D2-D3 & $-3.9(35.9)$ & $+5.0(29.7)$ & $<0.01$ \\
\hline PCT at D4 $(n=121 ; 80 S, 41 N S)^{a}$ & $17.3(45.8)$ & $32.4(46.2)$ & 0.03 \\
\hline$\triangle \mathrm{PCT}$ D1-D4 & $-9.1(46.7)$ & $-0.8(102.5)$ & 0.01 \\
\hline$\triangle \mathrm{PCT}$ D3-D4 & $-8.3(21.5)$ & $-8.4(16.6)$ & 0.97 \\
\hline
\end{tabular}

Changes in procalcitonin (PCT) values at various time points in patients with bacterial sepsis according to the appropriateness of the first-line empirical antibiotic therapy. S, survivors; NS, nonsurvivors. $\triangle$ PCT D1-D2, procalcitonin decrease between day 2 and day 1 after the onset of sepsis, and so forth. aMissing data are due to insufficient serum sample or death of patients within the 1-day, 2-day or 3-day-period following the onset of sepsis. D1, day sepsis is diagnosed. 
Table 3

Factors predictive of the appropriateness of first-line empirical antibiotic therapy in patients with bacterial sepsis

\begin{tabular}{lllll}
\hline & Odds ratio & Variable type & $95 \%$ confidence interval & $P$ value \\
\hline Gram staining (positive) & 2.61 & Dichotomous & 1.13 to 6.03 & 0.02 \\
$\Delta$ PCT D2-D3 & 10.29 & Continuous & 1.66 to 63.9 & 0.01
\end{tabular}

Multivariate analysis of factors predictive of the appropriateness of the first-line empirical antibiotic therapy in 147 patients with bacterial sepsis. PCT, procalcitonin; D1, day sepsis is diagnosed; $\triangle$ PCT D2-D3, procalcitonin decrease between day 3 and day 2 after the onset of sepsis.

\section{Survival analysis}

The crude ICU 28 day-mortality was $24.4 \%$ in the study population. Age, SAPS II value on admission and SOFA score on the first day of sepsis were found to be associated with an unfavorable outcome (Table 1). Septic shock at the onset of sepsis was also more frequent in nonsurvivors than survivors (63.3\% vs. $32.8 \%$, respectively; $P<0.01$ ). In addition, these nonsurviving patients were more likely to present with pneumonia and to suffer from Gram-negative infection than were survivors. Among biological and physiological variables, the serum lactates and the platelet count were found to be significantly different between survivors and nonsurvivors.

In contrast, neither the PCT baseline value (that is, the D1 value) nor the D2 value was associated with death in the study population despite a trend toward greater values in the nonsurvivors (Table 5). PCT was found to be significantly higher, however, in nonsurvivors than in survivors by D3 and D4. The $\triangle$ PCT D2-D3 value was calculated for only 147 patients because of missing data and because of the death of some patients within this period. $\triangle$ PCT D2-D3 was found to be an independent predictor of a bad outcome. In addition, a $\triangle \mathrm{PCT}$ D2-D3 lower than $-30 \%$ was associated with death in our study (log-rank test: $P=0.04$ ) (Figure 1). $\triangle$ PCT D2-D3 was also found to be an independent predictor of a bad outcome in our multivariate analysis (odds ratio $=2.94 ; 95 \%$ confidence interval $=1.22$ to $7.09 ; P=0.02$ ) (Table 6$)$.

The predictive value of $\triangle \mathrm{PCT}$ D2-D3 was compared with that of the SOFA score on D1 through construction of the corresponding ROC curves. It is worth noting that the areas under the receiver operating characteristic curve achieved by both markers were comparable (mean (standard deviation)) 0.697 (0.051) and $0.713(0.048)$, respectively; $P=$ not significant) (Figure 2). In addition, we found that the combination of the two led to a significant, although slight, improvement in the predictive value of each factor taken alone (mean (standard deviation)) area under the receiver operating characteristic curve $=0.758(0.048)$ (Figure 3)

\section{Discussion}

We show herein that the PCT kinetic within the first 48 hours of management of sepsis could be significantly different according to the appropriateness of the first-line empirical antibiotic therapy. Actually, PCT variations between D2 and

Figure 1

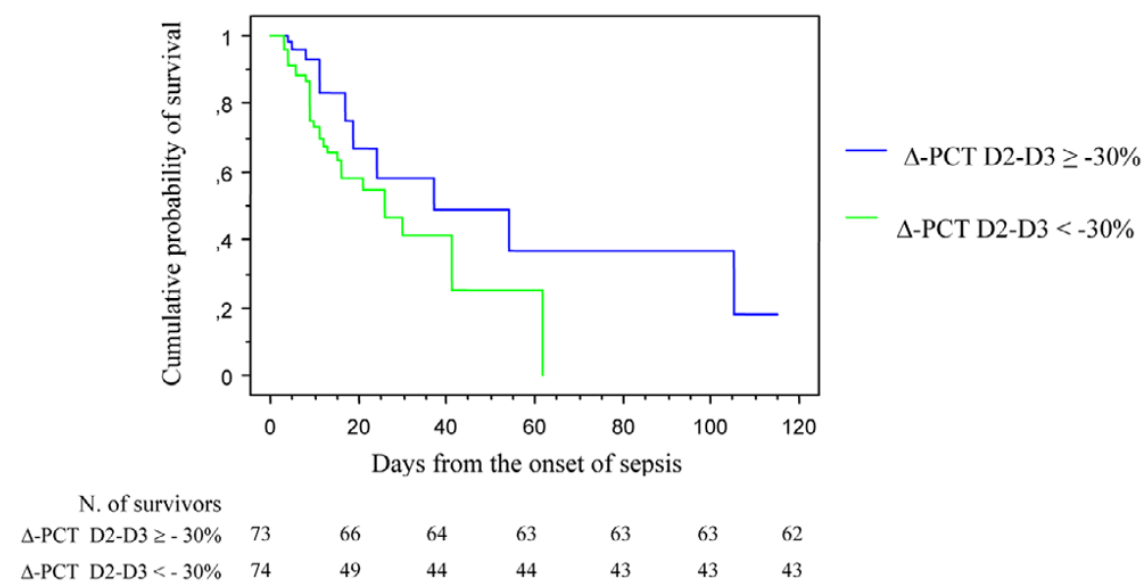

Kaplan-Meier estimated survival after the onset of bacterial sepsis. Kaplan-Meier estimated survival in the intensive care unit after the onset of bacterial sepsis in 147 patients with bacterial sepsis according to the procalcitonin variation between day 3 and day 2 (log-rank test, $P=0.04$ ). D1, day sepsis is diagnosed; $\triangle$ PCT D2-D3, procalcitonin decrease between day 3 and day 2 after the onset of sepsis. 
Time course to endpoints other than procalcitonin in bacterial sepsis patients according to antibiotic therapy

\begin{tabular}{|c|c|c|c|}
\hline & \multicolumn{2}{|c|}{ First-line empirical antibiotic therapy } & \multirow[t]{2}{*}{$P$ value } \\
\hline & Appropriate & Inappropriate & \\
\hline \multicolumn{4}{|l|}{ D1 } \\
\hline SOFA score (points) & $6.2(3.5)$ & $6.4(4.0)$ & 0.77 \\
\hline Mean arterial pressure $(\mathrm{mmHg})$ & $74.2(18.7)$ & $71.3(21.3)$ & 0.41 \\
\hline Platelet count (giga/l) & $201.4(123.0)$ & $231.4(175.2)$ & 0.23 \\
\hline Creatininemia $(\mu \mathrm{mol} / \mathrm{l})$ & $197.7(184.2)$ & $203.6(173.5)$ & 0.85 \\
\hline Lactate $(\mathrm{mmol} / \mathrm{l})$ & $3.4(3.2)$ & $2.8(1.8)$ & 0.26 \\
\hline $\mathrm{PO}_{2} / \mathrm{FiO}_{2}(\mathrm{mmHg})$ & $229(129)$ & $280(163)$ & 0.05 \\
\hline C-reactive protein (mg/l) & $159.9(112.9)$ & $121.1(105.0)$ & 0.11 \\
\hline \multicolumn{4}{|l|}{ D2 } \\
\hline SOFA score (points) & $6.0(3.8)$ & $6.1(4.3)$ & 0.89 \\
\hline Mean arterial pressure $(\mathrm{mmHg})$ & $78.6(18.6)$ & $76.2(18.7)$ & 0.48 \\
\hline Platelet count (giga/l) & $193.0(128.9)$ & $194.8(159.9)$ & 0.94 \\
\hline Creatininemia $(\mu \mathrm{mol} / \mathrm{l})$ & $183.9(175.7)$ & $206.0(185.5)$ & 0.49 \\
\hline Lactate $(\mathrm{mmol} / \mathrm{l})$ & $2.8(2.8)$ & $2.1(0.8)$ & 0.15 \\
\hline $\mathrm{PO}_{2} / \mathrm{FiO}_{2}(\mathrm{mmHg})$ & $252(132)$ & $251(129)$ & 0.96 \\
\hline C-reactive protein (mg/l) & $171.7(101.8)$ & $159.3(86.6)$ & 0.59 \\
\hline \multicolumn{4}{|l|}{ D3 } \\
\hline SOFA score (points) & $5.5(4.0)$ & $5.7(4.2)$ & 0.73 \\
\hline Mean arterial pressure $(\mathrm{mmHg})$ & $82.3(19.1)$ & $78.2(22.3)$ & 0.26 \\
\hline Platelet count (giga/l) & $192.1(127.6)$ & $177.6(144.2)$ & 0.55 \\
\hline Creatininemia $(\mu \mathrm{mol} / \mathrm{l})$ & $173.0(151.9)$ & $199.9(189.3)$ & 0.35 \\
\hline Lactate $(\mathrm{mmol} / \mathrm{l})$ & $2.4(2.8)$ & $1.8(0.7)$ & 0.24 \\
\hline $\mathrm{PO}_{2} / \mathrm{FiO}_{2}(\mathrm{mmHg})$ & $263(120.7)$ & $275(108.6)$ & 0.61 \\
\hline C-reactive protein (mg/l) & $176.4(116.4)$ & $160.0(86.1)$ & 0.53 \\
\hline \multicolumn{4}{|l|}{ D4 } \\
\hline SOFA score (points) & $4.5(3.8)$ & $5.8(3.9)$ & 0.24 \\
\hline Mean arterial pressure $(\mathrm{mmHg})$ & $81.1(26.8)$ & $77.0(14.1)$ & 0.53 \\
\hline Platelet count (giga/l) & $189.8(139.3)$ & $135.8(122.9)$ & 0.14 \\
\hline Creatininemia $(\mu \mathrm{mol} / \mathrm{l})$ & $181.1(161.4)$ & $216.6(166.7)$ & 0.39 \\
\hline Lactate $(\mathrm{mmol} / \mathrm{l})$ & $2.6(3.5)$ & $1.5(0.5)$ & 0.09 \\
\hline $\mathrm{PO}_{2} / \mathrm{FiO}_{2}(\mathrm{mmHg})$ & $249(122.5)$ & $276(79)$ & 0.36 \\
\hline C-reactive protein (mg/l) & $139.8(103.7)$ & $122.2(74.5)$ & 0.48 \\
\hline
\end{tabular}

Time course of relevant endpoints other than procalcitonin in patients with bacterial sepsis according to appropriateness of first-line empirical antibiotic therapy. SOFA, Sepsis-related Organ Failure Assessment; D1, day sepsis is diagnosed.

D3 were shown to be critical since a significantly greater PCT decline within this period was expected in the patients with appropriate empirical antibiotic therapy. In addition, a trend toward a greater rise in PCT between D1 and D2 was observed in patients with inappropriate antibiotics as com- pared with those with appropriate therapy. As a result, our findings suggest that patient management might be reassessed if PCT does not decrease by $30 \%$ between D2 and D3. In such cases, empirical antibiotic therapy modification 
Table 5

Procalcitonin changes at various time points in patients with bacterial sepsis according to the outcome

\begin{tabular}{|c|c|c|c|}
\hline & Survivors & Nonsurvivors & $P$ value \\
\hline PCT at D1 $(n=180 ; 129 \mathrm{~S}, 51 \mathrm{NS})^{\mathrm{a}}$ & $21.7(52.0)$ & $43.0(107.4)$ & 0.30 \\
\hline PCT at D2 $(n=163 ; 117 \mathrm{~S}, 46 \mathrm{NS})^{a}$ & $25.7(41.5)$ & $43.9(76.3)$ & 0.13 \\
\hline$\triangle \mathrm{PCT}$ D1-D2 & $+1.8(35.9)$ & $+4.8(44.6)$ & 0.44 \\
\hline PCT at D3 $(n=164 ; 117 \mathrm{~S}, 47 \mathrm{NS})^{a}$ & $21.3(41.0)$ & $40.8(85.7)$ & 0.04 \\
\hline$\triangle \mathrm{PCT}$ D2-D3 & $-4.5(24.0)$ & $+5.4(52.3)$ & $<0.01$ \\
\hline PCT at D4 $(n=121 ; 80 S, 41 N S)^{a}$ & $14.0(29.1)$ & $34.9(66.6)$ & $<0.01$ \\
\hline$\triangle \mathrm{PCT}$ D1-D4 & $-3.2(38.8)$ & $-14.1(97.8)$ & 0.05 \\
\hline$\triangle \mathrm{PCT}$ D3-D4 & $-5.9(14.8)$ & $-13.1(28.2)$ & 0.06 \\
\hline
\end{tabular}

S, survivors; NS, nonsurvivors; PCT, procalcitonin; D1, day sepsis is diagnosed; $\triangle \mathrm{PCT} D 1-\mathrm{D} 2$, procalcitonin decrease between day 2 and day 1 after the onset of sepsis, and so forth. aMissing data are due to insufficient serum samples or death of patients within the 1-day, 2-day or 3-day period following the onset of sepsis.

towards a broader spectrum should be considered while the microbiological findings, if any, are still pending.

Since the adequacy of early management of critically ill patients with sepsis including antibiotic administration is thought to be critical, objective markers are required. Given the lack of reliability of clinical endpoints such as body temperature, biomarkers are of potential interest. Among them, PCT has appeared as one of the most promising in the setting of severe bacterial sepsis [22]. Only a few studies about the early time-dependent changes of PCT have so far been published, and none of them focused on the appropriateness of the firstline antibiotic therapy. Some experimental data do, however, support the fact that PCT elevation is related to the bacterial load [23]. PCT kinetics during the first days of sepsis could therefore reflect the efficacy of the host immune response with respect to bacterial clearance, with or without the contribution of an appropriate antibiotic therapy. The clinical relevance of such an explanation has already been demonstrated, but only at the late stage of sepsis management (that is, once the continuation of antibiotic therapy becomes a matter of concern) $[13,14]$.
Only one published study provides data about PCT variations according to the adequacy of the empirical antibiotic therapy [24]. In the setting of VAP, these authors failed to demonstrate any difference in either PCT or C-reactive protein variations within the first 5 days of management in patients to whom appropriate treatment was promptly given compared with others. In contrast, a recently published study has shown that a C-reactive protein decline could be more rapidly achieved if empirical antibiotic therapy was effective against the microorganism that was subsequently identified as responsible for the VAP episode [25]. Unfortunately, however, PCT was not measured in that study despite the faster than expected kinetics. As a result, one could argue that the clinical utility of biomarkers is limited since the microbiological findings, if any, are usually available before the fifth day following the onset of sepsis. Our findings, however, suggest that daily monitoring of PCT could be useful to assess the appropriateness of the empirical antibiotic therapy at an earlier stage (that is, within the first 48 hours of management).

Besides these findings, we showed that a decrease of $30 \%$ at

Table 6

Multivariate analysis of prognosis factors of outcome in 147 patients with bacterial sepsis

\begin{tabular}{lllll}
\hline & Odds ratio & Variable type & $95 \%$ confidence interval & $P$ value \\
\hline Age (years) & 1.05 & Continuous & 1.02 to 1.08 & $<0.01$ \\
SOFA score by day 1 & 1.28 & Continuous & 1.12 to 1.45 & $<0.01$ \\
SPCT D2-D3 $>-30 \%$ & 2.94 & Dichotomous & 1.22 to 7.09 & 0.02 \\
Lung source of infection & 3.14 & Dichotomous & 1.40 to 8.26 & 0.01 \\
\hline
\end{tabular}

SOFA, Sepsis-related Organ Failure Assessment; D1, day sepsis is diagnosed; $\triangle$ PCT D2-D3, procalcitonin decrease between day 3 and day 2 after the onset of sepsis. 
Figure 2

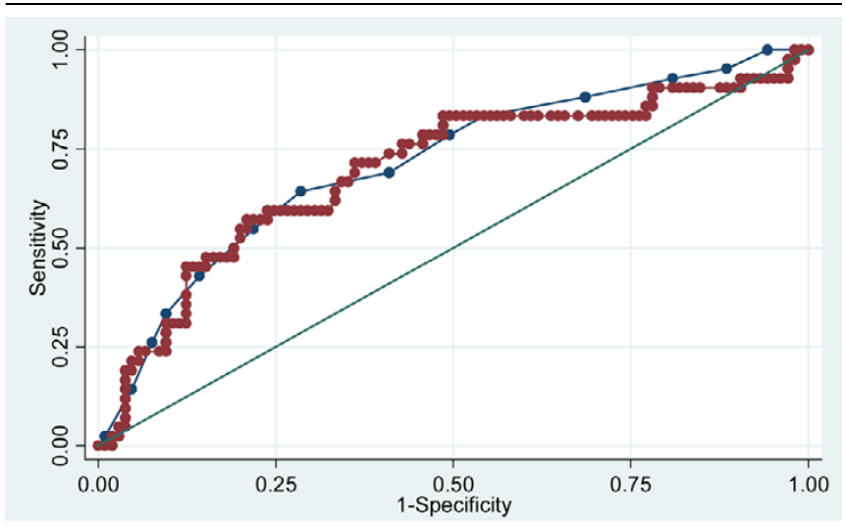

Procalcitonin variation and Sepsis-related Organ Failure Assessment for differentiating between survivors and nonsurvivors. Receiver operating characteristic curves of procalcitonin variation between day 2 and day 3 after the onset of sepsis (red line) and Sepsis-related Organ Failure Assessment (blue line) for differentiating between survivors and nonsurvivors in the intensive care unit in 147 patients with bacterial sepsis. Area under the receiver operating characteristic curve $=0.713$ (0.048) and $0.697(0.051)$ (mean (standard deviation)), respectively $(P$ $=0.80$ ).

least was associated with survival. Although low, the predictive value of $\triangle P C T$ D2-D3 regarding the outcome was comparable with those of the D1 SOFA score. In contrast, the rise in PCT we generally noticed between D1 and D2 did not appear as a relevant indicator of prognosis. Some authors have reported that the PCT baseline value could differentiate survivors from nonsurvivors in patients with sepsis, while others found that only the level achieved several days later could differentiate the two patient groups [17-19,21]. Differences in Figure 3

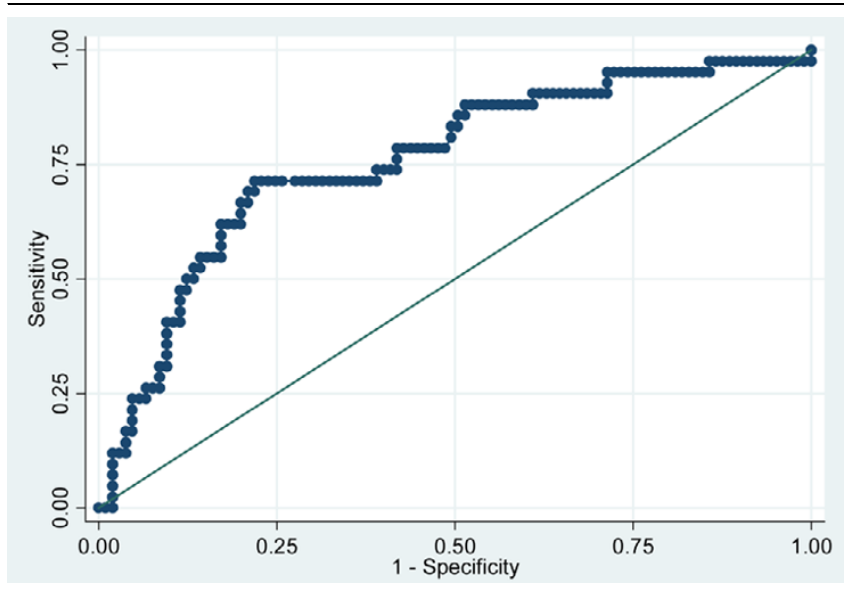

Procalcitonin variation in combination with Sepsis-related Organ Failure Assessment for differentiating between survivors and nonsurvivors. Receiver operating characteristic curves of procalcitonin variation between day 2 and day 3 after the onset of sepsis in combination with Sepsis-related Organ Failure Assessment for differentiating between survivors and nonsurvivors in the intensive care unit in 163 patients with bacterial sepsis. Area under the receiver operating characteristic curve $=0.758(0.048)$ (mean (standard deviation)). the case mix as well as the small size of the study groups could account for such discrepancies. In addition, variations regarding the respective proportions of Gram-negative and Grampositive bacteria as well as the isolation of yeast in the included patients could offer some additional explanations $[26,27]$. Previous reports have also pointed out that PCT kinetics, rather than the baseline or the peak values, correlate with patient outcome [28]. Some authors have therefore reported that if PCT remained elevated in critically ill patients with sepsis, then the risk of death was increased, sometimes regardless of the absolute levels $[15,16,29]$.

Although these findings provide a consistent overview of the time course of PCT levels in the patients with sepsis according to the outcome, however, drawing parallels with daily clinical practice remains difficult. Accordingly, changes with time were accurately analyzed in only very few of them. Interestingly, in a study involving 53 patients with septic shock, some authors showed that the rate of PCT decrease (that is, a decrease of $25 \%$ at least from baseline value) by D3 was greater in the survivors than in the patients with an unfavorable outcome [20]. Another study investigated the daily kinetics of PCT alone or in combination with other prognosis indicators in 72 patients with septic shock [30]. They found that the combination of an increase in PCT and lactates between D1 and D2 was the best predictor of 28-day mortality, whereas no difference was found when these markers were considered alone. The increase in PCT, however, was not defined in this study.

A study of 75 patients with VAP showed that a decrease in PCT between D5 and baseline (simply defined as a negative $\Delta$ value) could predict a good outcome [24]. Similar results were obtained in 100 patients with severe communityacquired pneumonia by comparing D3 PCT levels with baseline values [31]. Unfortunately, PCT was not measured earlier by the authors of the two latter studies. In addition, the LumiTest ${ }^{\circledR}$ (Brahms) was used for PCT measurement in all of these reports, despite lower functional sensitivity when compared with the Kryptor ${ }^{\circledR}$ immunoassay as used in the present study. As a result, PCT variations in patients with low baseline values might be questionable.

It is worth noting that survival was not influenced by the appropriateness of the empirical antibiotic therapy. The fact that the treatment was modified in most patients as early as D2 of sepsis (85.6\% of appropriate antibiotic therapy at this time point) may account for this finding. In addition, this could reflect the fact that, in some cases, antibiotic therapy has been modified because of an undesirable course of PCT within this time frame, such as a high $\triangle P C T$ D1-D2. Another explanation could be that microbiological findings were available earlier (that is, before D2) in some patients since routine cultures are performed regularly in our ICU. Accordingly, sepsis was more likely to be nosocomial in the patients who were given inappropriate therapy. 
Several limitations of our study have to be mentioned. First, the small size of our sample could account for our failure to demonstrate some statistically significant difference between the patients with or without appropriate first-line empirical antibiotic therapy while obvious trends have arisen from our results. This is especially true when considering the difference of $\triangle P C T$ D1-D2 between these patients. Second, the present investigation was a single-center study. Any generalization of our data should therefore be cautious. In addition, given the study design, there was a high proportion of missing data. As a result, although excluded patients did not differ from those included in terms of age and severity, one cannot exclude the possibility that PCT values did not follow the same distribution as in the analyzed cohort. Such a weakness is also the strength of our study, however, since PCT dosages were performed in a real-life manner, in theory making it easier to translate our findings to clinical practice. Moreover, we cannot exclude the possibility that some confounding variables have been missed. Hence, although not significant, the higher levels of serum creatininemia could account for the differences between nonsurvivors and survivors with regard to the PCT levels we recorded, as has recently been reported [32].

\section{Conclusions}

Our findings suggest that PCT kinetics within the first 48 hours of sepsis management could be related to the appropriateness of first-line empirical antibiotic therapy as well as to the patient outcome. A prospective study is therefore required to assess the clinical relevance of such results. Actually, the daily variations in PCT in addition to the clinical findings could be used as a surrogate to assess the effectiveness of therapy and to trigger more aggressive therapies and diagnostic investigations in an attempt to improve outcome. As a part of this, broadening the spectrum of the empirical antibiotic therapy should be considered. Accordingly, this hypothesis is currently under investigation through a multicenter prospective interventional study [33].

\section{Key messages}

- The PCT time course within the first days of management of sepsis could be a critical issue in the critically ill patients.

- A marked decreased of PCT between the second and third days might be expected in the patients with appropriate empirical antibiotic therapy and good outcome.

\section{Competing interests}

PEC has received payments from Brahms (Hennigsdorf, Germany) to attend several meetings about sepsis management. The other authors declare that they have no competing interests.

\section{Authors' contributions}

PEC designed the study, analyzed the data and drafted the manuscript. SB and CT collected the data and participated in their interpretation. SA performed the statistical analysis. J$\mathrm{PQ}, \mathrm{J}-\mathrm{MD}, \mathrm{SP}$ and BB participated in critical revision of the manuscript. N-OO managed the activity of the Immunology Laboratory.

\section{References}

1. Annane D, Aegerter P, Jars-Guincestre MC, Guidet B: Current epidemiology of septic shock: the cub-rea network. $A m \mathrm{~J}$ Respir Crit Care Med 2003, 168:165-172.

2. Pittet D, Tarara D, Wenzel RP: Nosocomial bloodstream infection in critically ill patients. Excess length of stay, extra costs, and attributable mortality. JAMA 1994, 271:1598-1601.

3. Garrouste-Orgeas M, Timsit JF, Tafflet M, Misset B, Zahar JR, Soufir L, Lazard T, Jamali S, Mourvillier B, Cohen Y, De Lassence A, Azoulay E, Cheval C, Descorps-Declere A, Adrie C, Costa de Beauregard MA, Carlet J: Excess risk of death from intensive care unit-acquired nosocomial bloodstream infections: A reappraisal. Clin Infect Dis 2006, 42:1118-1126.

4. Munson EL, Diekema DJ, Beekmann SE, Chapin KC, Doern GV: Detection and treatment of bloodstream infection: Laboratory reporting and antimicrobial management. J Clin Microbiol 2003, 41:495-497.

5. Rivers E, Nguyen B, Havstad S, Ressler J, Muzzin A, Knoblich B, Peterson E, Tomlanovich M: Early goal-directed therapy in the treatment of severe sepsis and septic shock. N Engl J Med 2001, 345:1368-1377.

6. Luna CM, Aruj P, Niederman MS, Garzon J, Violi D, Prignoni A, Rios F, Baquero S, Gando S: Appropriateness and delay to initiate therapy in ventilator-associated pneumonia. Eur Respir J 2006, 27:158-164.

7. Munford RS, Pugin J: Normal responses to injury prevent systemic inflammation and can be immunosuppressive. $A m \mathrm{~J}$ Respir Crit Care Med 2001, 163:316-321.

8. Ibrahim EH, Sherman G, Ward S, Fraser VJ, Kollef MH: The influence of inadequate antimicrobial treatment of bloodstream infections on patient outcomes in the ICU setting. Chest 2000, 118:146-155.

9. Harbarth S, Garbino J, Pugin J, Romand JA, Lew D, Pitet D: Inappropriate initial antimicrobial therapy and its effect on survival in a clinical trial of immunomodulating therapy for severe sepsis. Am J Med 2003, 115:529-535.

10. Christ-Crain M, Muller B: Procalcitonin in bacterial infections hype, hope, more or less? Swiss Med Wkly 2005, 135:451-460.

11. Riche FC, Cholley BP, Panis YH, Laisne MJ, Briard CG, Graulet AM, Gueris JL, Valleur PD: Inflammatory cytokine response in patients with septic shock secondary to generalized peritonitis. Crit Care Med 2000, 28:433-437.

12. Bonten MJ, Froon AH, Gaillard CA, Greve JW, de Leeuw PW, Drent M, Stobberingh EE, Buurman WA: The systemic inflammatory response in the development of ventilator-associated pneumonia. Am J Respir Crit Care Med 1997, 156:1105-1113.

13. Christ-Crain M, Stolz D, Bingisser R, Muller C, Miedinger D, Huber PR, Zimmerli W, Harbarth S, Tamm M, Muller B: Procalcitonin guidance of antibiotic therapy in community-acquired pneumonia: a randomized trial. Am J Respir Crit Care Med 2006, 174:84-93.

14. Nobre V, Harbarth S, Graf JD, Rohner P, Pugin J: Use of procalcitonin to shorten antibiotic treatment duration in septic patients: a randomized trial. Am J Respir Crit Care Med 2008, 177:498-505

15. Harbarth S, Holeckova K, Froidevaux C, Pittet D, Ricou B, Grau GE, Vadas L, Pugin J: Diagnostic value of procalcitonin, interleukin-6, and interleukin-8 in critically ill patients admitted with suspected sepsis. Am J Respir Crit Care Med 2001, 164:396-402.

16. Schroder J, Staubach KH, Zabel P, Stuber F, Kremer B: Procalcitonin as a marker of severity in septic shock. Langenbecks Arch Surg 1999, 384:33-38. 
17. Gibot S, Cravoisy A, Kolopp-Sarda MN, Bene MC, Faure G, Bollaert PE, Levy B: Time-course of sTREM (soluble triggering receptor expressed on myeloid cells)-1, procalcitonin, and Creactive protein plasma concentrations during sepsis. Crit Care Med 2005, 33:792-796.

18. Meisner M, Tschaikowsky K, Palmaers T, Schmidt J: Comparison of procalcitonin (pct) and c-reactive protein (crp) plasma concentrations at different sofa scores during the course of sepsis and mods. Crit Care 1999, 3:45-50.

19. Luyt CE, Guerin V, Combes A, Trouillet JL, Ayed SB, Bernard M, Gibert C, Chastre J: Procalcitonin kinetics as a prognostic marker of ventilator-associated pneumonia. Am J Respir Crit Care Med 2005, 171:48-53.

20. Claeys R, Vinken S, Spapen H, ver Elst K, Decochez K, Huyghens $\mathrm{L}$, Gorus FK: Plasma procalcitonin and C-reactive protein in acute septic shock: clinical and biological correlates. Crit Care Med 2002, 30:757-762.

21. Clec'h C, Ferriere F, Karoubi P, Fosse JP, Cupa M, Hoang P, Cohen Y: Diagnostic and prognostic value of procalcitonin in patients with septic shock. Crit Care Med 2004, 32:1166-1169.

22. Becker KL, Snider R, Nylen ES: Procalcitonin assay in systemic inflammation, infection, and sepsis: clinical utility and limitations. Crit Care Med 2008, 36:941-952.

23. Nylen ES, Whang KT, Snider RH Jr, Steinwald PM, White JC, Becker KL: Mortality is increased by procalcitonin and decreased by an antiserum reactive to procalcitonin in experimental sepsis. Crit Care Med 1998, 26:1001-1006.

24. Seligman R, Meisner M, Lisboa TC, Hertz FT, Filippin TB, Fachel $\mathrm{JM}$, Teixeira PJ: Decreases in procalcitonin and C-reactive protein are strong predictors of survival in ventilator-associated pneumonia. Crit Care 2006, 10:R125.

25. Lisboa T, Seligman R, Diaz E, Rodriguez A, Teixeira PJ, Rello J: Creactive protein correlates with bacterial load and appropriate antibiotic therapy in suspected ventilator-associated pneumonia. Crit Care Med 2008, 36:166-171.

26. Charles PE, Dalle F, Aho S, Quenot JP, Doise JM, Aube H, Olsson NO, Blettery B: Serum procalcitonin measurement contribution to the early diagnosis of candidemia in critically ill patients. Intensive Care Med 2006, 32:1577-1583.

27. Charles PE, Ladoire S, Aho S, Quenot JP, Doise JM, Prin S, Olsson NO, Blettery B: Serum procalcitonin elevation in critically ill patients at the onset of bacteremia caused by either gram negative or gram positive bacteria. BMC Infect Dis 2008, 8:38.

28. Jensen JU, Heslet L, Jensen TH, Espersen K, Steffensen P, Tvede $M$ : Procalcitonin increase in early identification of critically ill patients at high risk of mortality. Crit Care Med 2006, 34:2596-2602.

29. Bossink AW, Groeneveld AB, Thijs LG: Prediction of microbial infection and mortality in medical patients with fever: plasma procalcitonin, neutrophilic elastase-alpha1-antitrypsin, and lactoferrin compared with clinical variables. Clin Infect Dis 1999, 29:398-407.

30. Phua J, Koay ES, Lee KH: Lactate, procalcitonin, and amino-terminal pro-B-type natriuretic peptide versus cytokine measurements and clinical severity scores for prognostication in septic shock. Shock 2008, 29:328-333.

31. Boussekey N, Leroy O, Alfandari S, Devos P, Georges H, Guery B: Procalcitonin kinetics in the prognosis of severe communityacquired pneumonia. Intensive Care Med 2006, 32:469-472.

32. Amour J, Birenbaum A, Langeron $O$, Le Manach $Y$, Bertrand $M$, Coriat $P$, Riou B, Bernard M, Hausfater P: Influence of renal dysfunction on the accuracy of procalcitonin for the diagnosis of postoperative infection after vascular surgery. Crit Care Med 2008, 36:1147-1154.

33. Jensen JU, Lundgren B, Hein L, Mohr T, Petersen PL, Andersen LH, Lauritsen AO, Hougaard S, Mantoni T, Bømler B, Thornberg KJ, Thormar K, Løken J, Steensen M, Carl P, Petersen JA, Tousi H, Søe-Jensen $\mathrm{P}$, Bestle M, Hestad S, Andersen MH, Fjeldborg P, Larsen KM, Rossau C, Thomsen CB, Ostergaard C, Kjaer J, Grarup J, Lundgren JD: The Procalcitonin And Survival Study (PASS) - a randomised multi-center investigator-initiated trial to investigate whether daily measurements biomarker Procalcitonin and pro-active diagnostic and therapeutic responses to abnormal Procalcitonin levels, can improve survival in intensive care unit patients. Calculated sample size (target population): 1000 patients. BMC Infect Dis 2008, 8:91. 